\title{
Author Correction: Full-gap superconductivity in spin-polarised surface states of topological semimetal $\beta-\mathrm{PdBi}_{2}$
}

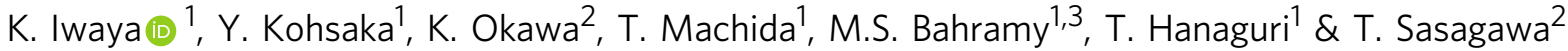

Nature Communications 8:976 10.1038/s41467-017-01209-9; Article published online: 17 October 2017

This Article contains an error in Fig. 3 in that the calculated patterns of quasiparticle interference in the figure are incorrect due to the wrong Wannier transformation in the calculation process. The correct version of Fig. 3 appears below. This correction does not affect the discussion or the conclusion of the Article.

Published online: 14 December 2017

\begin{abstract}
(c) (i) Open Access This article is licensed under a Creative Commons Attribution 4.0 International License, which permits use, sharing, adaptation, distribution and reproduction in any medium or format, as long as you give appropriate credit to the original author(s) and the source, provide a link to the Creative Commons license, and indicate if changes were made. The images or other third party material in this article are included in the article's Creative Commons license, unless indicated otherwise in a credit line to the material. If material is not included in the article's Creative Commons license and your intended use is not permitted by statutory regulation or exceeds the permitted use, you will need to obtain permission directly from the copyright holder. To view a copy of this license, visit http://creativecommons.org/licenses/by/4.0/.
\end{abstract}

(C) The Author(s) 2017

\footnotetext{
${ }^{1}$ RIKEN Center for Emergent Matter Science, Wako, Saitama 351-0198, Japan. ${ }^{2}$ Laboratory for Materials and Structures, Tokyo Institute of Technology, Yokohama, Kanagawa 226-8503, Japan. ${ }^{3}$ Department of Applied Physics, The University of Tokyo, Hongo, Bunkyo-ku, Tokyo 113-8656, Japan.

Correspondence and requests for materials should be addressed to K.I. (email: iwaya@riken.jp) or to T.H. (email: hanaguri@riken.jp)
} 
a

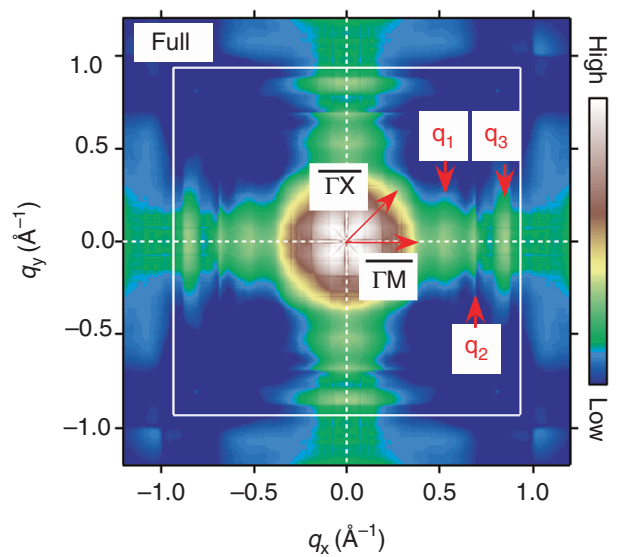

b

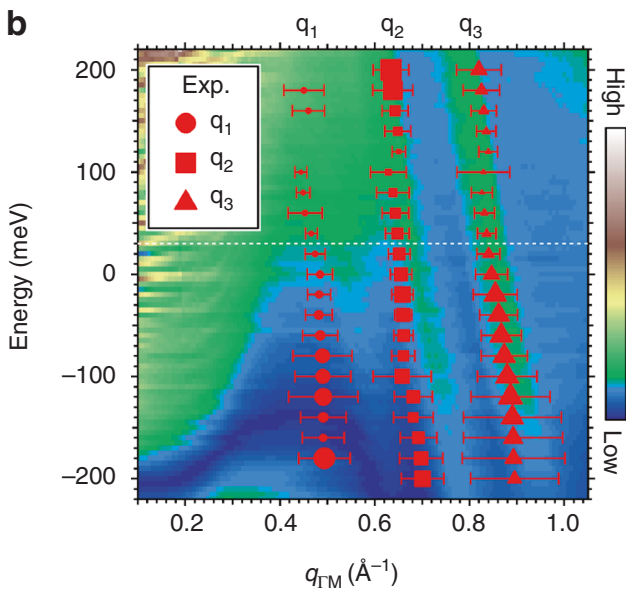

C

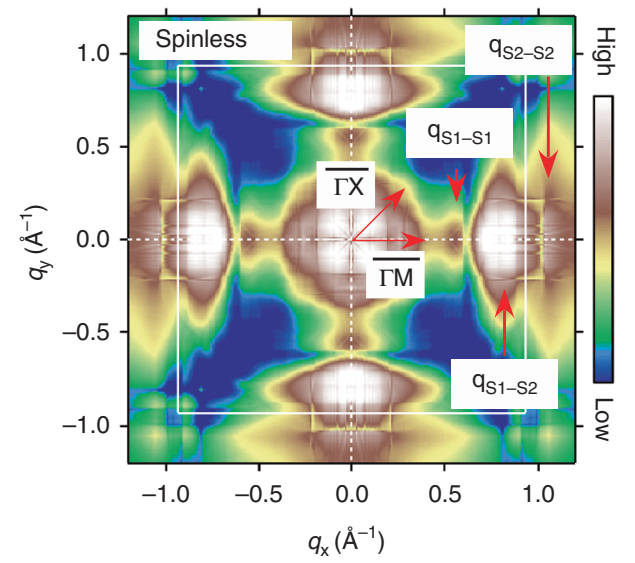

d

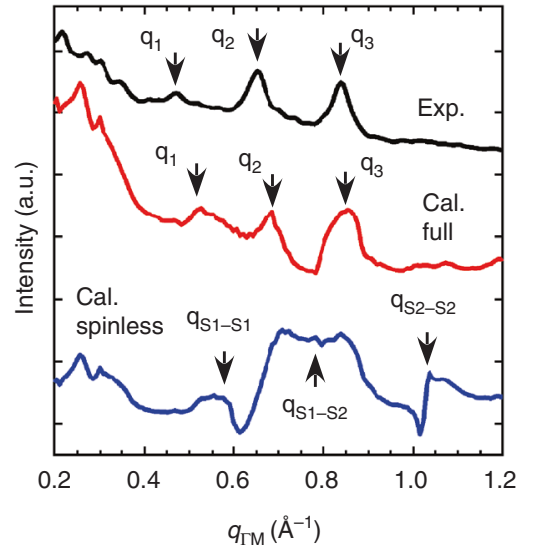

Fig. 3 